\title{
R\&D and wholesale trade are critical to the economy: Identifying dominant sectors from economic networks*
}

\author{
Mardi Dungey and Vladimir Volkov \\ Tasmanian School of Business and Economics, University of Tasmania
}

October 2017

\begin{abstract}
Using a network approach we identify critical sectors for 49 economies. Wholesale trade is dominant for over half the countries, but increasingly $\mathrm{R} \& \mathrm{D}$ activities have an equivalent importance. Recognizing $\mathrm{R} \& \mathrm{D}$ as critical urges caution against disinvesting in this sector.
\end{abstract}

Keywords: Networks, input-output tables, sectors, research and development

JEL Classification Numbers: C67, O30, D57, C23

Corresponding author: Mardi Dungey, Tasmanian School of Business and Economics, Private Bag 85, Hobart, Tasmania 7001, Australia.

Ph: +61 362261839

email: mardi.dungey@utas.edu.au

(c) 2018. This manuscript version is made available under the CC-BY-NC-ND 4.0 license http://creativecommons.org/licenses/by-nc-nd/4.0/

https://doi.org/10.1016/j.econlet.2017.11.007

${ }^{*}$ The authors thank Hashem Pesaran and Cynthia Yang for useful comments and Loveth Ochayi for research assistance. We acknowledge funding from ARC DP150101716. 


\section{Introduction}

Sectoral shocks have been established as a significant source of business cycle variation in the US economy, Gabaix (2011). While large sectors and/or firms can have large effects due to their size, Foerster et al. (2011) show that it is the networks of connections between the firms and sectors, represented by the covariation between the sectors, which have critical effects. These economy-wide sectoral networks are formally modeled in Acemoglu et al. (2012). ${ }^{1}$

Using network theory to develop a formal test to determine the most critical sectors in the economy Pesaran and Yang (2017) establish the dominance of the wholesale trade and transport sector in the US economy. (Dominance is a formally defined term for sectors which pass the threshold value for critical importance in the network.) Ultimately, if stores cannot source or transport goods they cannot be distributed to their consumers. If manufacturers cannot transport products then they cannot sell their output and hence remain in business. This is a primary reason that modern conflict and war almost always pinpoint key transport linkages (roads, ports, trains, energy supplies) as primary targets to maximize disruption to opponents. Nordhaus (2002) highlights strong productivity growth in the wholesale trade sector as a major contributor to overall productivity growth in the 1990s.

We apply the dominant sector detection methodology of Pesaran and Yang (2017) to inputoutput tables for 49 economies and determine that in many of the more developed markets both $\mathrm{R} \& \mathrm{D}$ and wholesale trade are critical. For a substantial number of countries, including the US, the most recent data indicates a shift towards $R \& D$ as the dominant sector. The empirical work on sector dominance has not previously considered the importance of the R\&D activities as a key industry in sustaining the economy despite its long-established importance as key in the endogenous growth literature; Coe and Helpman (1995), Perez-Sebastian (2015).

These results should give rise to cautionary thought amongst countries which are considering reducing their investment in research and development in favor of perhaps more politically appealing infrastructure such as roads and trains. These are not unimportant, but running down public and private incentives to invest in $R \& D$ will be as equivalently misguided as neglecting more physically obvious networks for developed economies.

\section{Approach}

To characterize the effect of unit specific shocks on aggregate output consider the production network model of Acemoglu et al. (2012) in which production of sector $i$ at time $t, q_{i t}$, is determined by the following Cobb-Douglas production function subject to constant returns to scale

$$
q_{i t}=\exp \left(\alpha u_{i t}\right) l_{i t}^{\alpha} \prod_{j=1}^{N} q_{i j, t}^{\rho w_{i j}}, \quad \text { for } i=1, \ldots, N ; \quad t=1,2, \ldots, T,
$$

\footnotetext{
${ }^{1}$ Ando (2014) confirms that US sectoral shocks contribute significantly to the US aggregate output fluctuation and demonstrates the importance of including all relevant sectors in order to avoid bias from excluded nodes.
} 
where productivity shocks, $u_{i t}=\varepsilon_{i t}+\gamma_{i} f_{t}$, are determined by a sector-specific shock, $\varepsilon_{i t}$, and a common technological factor, $f_{t}$; labor input is denoted $l_{i t}$, with the share of labor given by $\alpha=1-\rho$, and $\rho w_{i j}$ is the share of output $j$ in the sector $i$. Following Pesaran and Yang (2017), the cross section exponent of the factor loadings $\delta_{\gamma}$ is defined to ensure that

$$
\lim _{N \rightarrow \infty} N^{-\delta_{\gamma}} \sum_{i=1}^{N}\left|\gamma_{i}\right|=c_{\gamma}>0
$$

where $c_{\gamma}$ is a finite constant ${ }^{2}$. Moreover, the sector specific shocks are assumed to be independent with zero means and finite variances.

The amount of final goods, $c_{i t}=q_{i t}-\sum_{j=1}^{N} q_{j i, t}$, is characterized by the amount of output of sector $j$ used in production of sector $i, q_{j i, t}$, and consumed by a representative households with the Cobb-Douglas preferences $u\left(c_{1 t}, \ldots, c_{N t}\right)=A \prod_{i=1}^{N} c_{i t}^{1 / N}, A>0$. We assume that the aggregate labor supply, $l_{t}$, is fixed and labor markets clear, $l_{t}=\sum_{i=1}^{N} l_{i t}$.

A price network is dual to the production network and the former is derived from the sectoral equilibrium prices $p_{i t}=\log \left(P_{i t}\right)$ and the equilibrium wage rates $\omega_{t}=\log (\text { Wage })_{t}$. Solving sector $i$ 's problem leads to

$$
\begin{aligned}
q_{i j, t} & =\frac{\rho w_{i j} P_{i t} q_{i t}}{P_{j t}}, \\
l_{i t} & =\frac{\alpha P_{i t} q_{i t}}{\text { Wage }_{t}} .
\end{aligned}
$$

Substituting equations (2) and (3) in (1) yields the price network ${ }^{3}$

$$
\mathbf{p}_{t}=\rho \mathbf{W} \mathbf{p}_{t}+\alpha \omega_{t} \tau_{N}-\left(\mathbf{b}+\alpha \gamma f_{t}+\alpha \varepsilon_{t}\right),
$$

in which $\mathbf{b}=\left(b_{1}, \ldots, b_{N}\right)^{\prime}$ is a vector of price-specific intercepts, $\mathbf{p}_{t}=\left(p_{1 t}, \ldots, p_{N t}\right)^{\prime}, \mathbf{W}=\left(w_{i j}\right)$ is a $N \times N$ matrix, $\tau_{N}$ is an $N$ dimensional vector of ones, $\gamma=\left(\gamma_{1}, \ldots, \gamma_{N}\right)^{\prime}$, and $\varepsilon_{t}=\left(\varepsilon_{1 t}, \ldots, \varepsilon_{N t}\right)^{\prime}$. Equations (2) and (4) can be used to obtain the sales equation

$$
\mathbf{S}_{t}=\rho \mathbf{W}^{\prime} \mathbf{S}_{t}+\mathbf{C}_{t}=\left(\mathbf{I}_{N}-\rho \mathbf{W}^{\prime}\right)^{-1} \mathbf{C}_{t}
$$

where $\mathbf{S}_{t}=\left(S_{1 t}, \ldots, S_{N t}\right)^{\prime}, \mathbf{C}_{t}=\left(C_{1 t}, \ldots, C_{N t}\right)^{\prime}, C_{i t}=P_{i t} c_{i t}$, and $S_{i t}=P_{i t} q_{i t}$. The right-hand side of equation (5) shows that the Leontief inverse captures network effects in the sales equation. These network effects, characterized by matrix $\mathbf{W}$, are the main object of interest.

Now consider a network represented by the adjacency matrix $\mathbf{W}=\left(w_{i j}\right)$ with non-negative elements for all $i$ and $j$ which is row-normalized ${ }^{4}$ such that $\sum_{j=1}^{N} w_{i j}=1$, for all $j$. To assess the effects of idiosyncratic shocks on some aggregate measure of the network we use out degree as a measure of centrality. In particular, the outdegree of the $j$ th unit, $d_{j}=\tau_{N}^{\prime} \mathbf{w}^{j}$, counts the

\footnotetext{
${ }^{2}$ This set up is different from the standard factor model as we allow the factor loadings to be random and do not assume $\delta_{\gamma}=1$.

${ }^{3}$ This form is clearly related to the spatial econometrics literature.

${ }^{4}$ The assumption that weights are normalized is standard in the network literature. See e.g. Diebold and Yilmaz (2014).
} 
number of ties the unit directs to others ${ }^{5}$ where $\mathbf{w}^{j}$ is assigned to the $j$ th column of $\mathbf{W}$. Pesaran and Yang (2017) showed that the network, represented by $\mathbf{W}$ with

$$
d_{j}=\kappa_{j} N^{\delta_{j}}
$$

where $\kappa_{j}$ is a fixed positive constant and $d_{j}>0$, contains a finite number of dominant units with $\delta_{j}$ being the degree of dominance of unit $j$. For unit-specific shocks to dominate the macro or common factor shocks we require $\delta_{i}>\delta_{\gamma}>0.5$. No network effects of unit-specific shocks can be identified ${ }^{6}$ when $\delta_{i} \leq 0.5$.

Under the exponent specification

$$
d_{i t}=\kappa N^{\delta_{i}} \exp \left(v_{i t}\right), \quad i=1, \ldots, N ; \quad t=1, \ldots, T,
$$

in which constant $\kappa>0, d_{i t}$ represent observations on outdegrees at time $t, v_{i t} \sim$ i.i.d. $\left(0, \sigma_{v}^{2}\right)$ over $i$ and $t$, a consistent estimator of the degree of pervasiveness of the dominant unit $\delta_{i}$ in the network where $T$ is finite and $N$ is large is defined as

$$
\hat{\delta}_{i}=\frac{T^{-1} \sum_{t=1}^{T} \ln \left(d_{i t}\right)-(T N)^{-1} \sum_{t=1}^{T} \sum_{j=1}^{N} \ln \left(d_{j t}\right)}{\ln (N)} .
$$

We estimate $\hat{\delta}_{i}$ from input-output tables of 49 countries between 1995 and 2011.

\section{Data}

We source domestic input-output tables for 49 countries over the period 1995 to 2011 from the World Economic Outlook database ${ }^{7}$. The countries are listed in Table 1. Annual data are used to construct 5 year panels (improving our estimation power over annual samples). We analyze the 36 sectors listed in Table 1 for each economy. Differing level of aggregation for sectors across applications will directly affect the estimated value $\hat{\delta}_{i}$. The assumption that each sector applies Cobb-Douglas technology, as in equation (1), implies that there is no strict additivity from lower to higher aggregation levels. The degree of aggregation in the OECD data means the results are not directly comparable with Pesaran and Yang (2017), who include over 400 sectors for the domestic US economy ( $R \& D$ is not separately identified), but are comparable across the different economies.

\section{Results}

Table 1 reports the sectors across 49 countries with the values of $\hat{\delta}_{i}$ for dominant sectors over the past 20 years from 5 year panels. Recall the condition that a dominant sector must have $\hat{\delta}_{i}>0.5$. In some countries more than one sector is dominant.

\footnotetext{
${ }^{5}$ This approach also shows that $d_{j}$ is a weighted measure of centrality.

${ }^{6}$ see Remark 3 of Pesaran and Yang (2017).

${ }^{7}$ Domestic input-output tables have been also analyzed by Bartelme and Gorodnichenko (2015), Fadinger et al. (2016) and Miranda-Pinto (2017). The annual data are available for 60 countries but are too sparse to implement this approach in 11 countries.
} 
Table 1: Sector related estimates of $\hat{\delta}_{i}$ from equation (8). The estimates in the second column are based on two years of data (1995-1996), while estimates in columns 3 to 5 are obtained from 5 year data panels. NA - no dominant sector. WS - wholesale and retail trade; RD - R\&D and other business activities; RE - real estate activities; BM - basic metals; TR - transport and storage; FI - financial intermediation; CP - coke, refined petroleum products and nuclear fuel; AC - agriculture, hunting, forestry and fishing; EL - electricity, gas and water supply; CH - chemicals and chemical products; MI - mining and quarrying; MA - machinery and equipment; PP - pulp, paper, paper products, printing and publishing; FP - Food products, beverages and tobacco; TE - Textiles, textile products, leather and footwear. China, Korea, Spain, Indonesia, Sweden, Germany, Czech Republic, and Finland have no dominant sectors over the sample.

\begin{tabular}{|c|c|c|c|c|}
\hline Country & 1996 & 2001 & 2006 & 2011 \\
\hline Argentina & $0.531(\mathrm{WS})$ & $0.549(\mathrm{WS})$ & $\mathrm{NA}$ & $\mathrm{NA}$ \\
\hline Australia & $0.589(\mathrm{WS})$ & $0.580(\mathrm{WS})$ & $0.578(\mathrm{WS})$ & $0.550(\mathrm{WS}) ; 0.501(\mathrm{RD})$ \\
\hline Austria & $0.502(\mathrm{WS})$ & NA & NA & NA \\
\hline Belgium & $0.529(\mathrm{WS})$ & $0.516(\mathrm{WS})$ & $0.521(\mathrm{WS}) ; 0.512(\mathrm{RD})$ & 0.519(RD);0.512(WS) \\
\hline Brazil & $0.523(\mathrm{FI}) ; 0.501(\mathrm{RD})$ & $0.512(\mathrm{RD})$ & $\mathrm{NA}$ & NA \\
\hline \multirow{2}{*}{ Brunei } & $0.708(\mathrm{MI}) ; 0.611(\mathrm{FP})$ & $0.866(\mathrm{MI}) ; 0.765(\mathrm{FP})$ & $0.857(\mathrm{FP}) ; 0.791(\mathrm{PP})$ & $0.867(\mathrm{MI}) ; 0.684(\mathrm{WS})$ \\
\hline & $0.594(\mathrm{TE})$ & $0.709(\mathrm{TR})$ & $0.734(\mathrm{WS})$ & $0.662(\mathrm{MA})$ \\
\hline Bulgaria & $0.588(\mathrm{WS}) ; 0.530(\mathrm{FI})$ & $0.508(\mathrm{WS})$ & $0.504(\mathrm{WS})$ & NA \\
\hline Cambodia & $0.549(\mathrm{WS})$ & NA & NA & NA \\
\hline Canada & NA & NA & NA & $0.538(\mathrm{WS})$ \\
\hline Colombia & $0.506(\mathrm{RD})$ & NA & NA & $\mathrm{NA}$ \\
\hline Costa Rica & $0.664(\mathrm{WS}) ; 0.545(\mathrm{TR})$ & $0.671(\mathrm{WS}) ; 0.511(\mathrm{TR})$ & $0.630(\mathrm{WS}) ; 0.503(\mathrm{FI})$ & $0.632(\mathrm{WS}) ; 0.542(\mathrm{FI})$ \\
\hline Croatia & $0.538(\mathrm{WS})$ & $0.524(\mathrm{WS})$ & $0.532(\mathrm{WS})$ & 0.506(RD);0.502(WS) \\
\hline Cyprus & $0.612(\mathrm{WS})$ & $0.605(\mathrm{WS})$ & $0.581(\mathrm{WS})$ & $0.610(\mathrm{WS})$ \\
\hline Denmark & $0.586(\mathrm{WS})$ & $0.576(\mathrm{WS})$ & $0.573(\mathrm{WS})$ & $0.598(\mathrm{WS}) ; 0.559(\mathrm{RD})$ \\
\hline Estonia & NA & NA & 0.509 (WS) & $0.520(\mathrm{WS})$ \\
\hline France & $0.501(\mathrm{RD})$ & $0.508(\mathrm{RD})$ & $0.538(\mathrm{RD})$ & $0.566(\mathrm{RD})$ \\
\hline Greece & $0.545(\mathrm{WS})$ & $0.577(\mathrm{WS})$ & $0.628(\mathrm{WS})$ & $0.641(\mathrm{WS})$ \\
\hline Hungary & NA & $0.505(\mathrm{WS})$ & NA & NA \\
\hline India & $0.513(\mathrm{BM})$ & $0.505(\mathrm{BM})$ & NA & NA \\
\hline Israel & NA & $0.502(\mathrm{WS})$ & NA & $0.522(\mathrm{RD})$ \\
\hline Italy & $0.530(\mathrm{WS})$ & $0.529(\mathrm{WS})$ & $0.529(\mathrm{WS})$ & $0.536(\mathrm{WS})$ \\
\hline Japan & $0.589(\mathrm{WS})$ & $0.583(\mathrm{WS})$ & $0.576(\mathrm{WS})$ & $0.568(\mathrm{WS})$ \\
\hline Lithuania & $0.548(\mathrm{WS}) ; 0.547(\mathrm{EL}) ; 0.534(\mathrm{TR})$ & $0.564(\mathrm{WS})$ & $0.548(\mathrm{WS})$ & $0.548(\mathrm{WS})$ \\
\hline Malaysia & $0.528(\mathrm{FI})$ & NA & NA & $0.542(\mathrm{WS}) ; 0.529(\mathrm{RD})$ \\
\hline Malta & $0.552(\mathrm{WS})$ & $0.513(\mathrm{WS})$ & $0.513(\mathrm{WS})$ & $0.541(\mathrm{WS}) ; 0.529(\mathrm{RD})$ \\
\hline Morocco & NA & $0.506(\mathrm{WS})$ & $0.533(\mathrm{WS})$ & $0.534(\mathrm{WS}) ; 0.518(\mathrm{FI})$ \\
\hline New Zealand & NA & $0.510(\mathrm{WS})$ & $0.516(\mathrm{WS})$ & $0.532(\mathrm{RD})$ \\
\hline Peru & $0.596(\mathrm{WS}) ; 0.562(\mathrm{TR})$ & $0.510(\mathrm{TR})$ & NA & NA \\
\hline Philippines & NA & $0.527(\mathrm{CP}) ; 0.506(\mathrm{WS})$ & $0.502(\mathrm{CP})$ & $0.536(\mathrm{CP}) ; 0.509(\mathrm{WS})$ \\
\hline Portugal & NA & $0.506(\mathrm{WS})$ & $0.507(\mathrm{WS})$ & NA \\
\hline Romania & NA & $0.548(\mathrm{WS})$ & NA & NA \\
\hline \multirow[t]{2}{*}{ Russia } & $0.682(\mathrm{WS}) ; 0.675(\mathrm{TR})$ & $0.704(\mathrm{WS}) ; 0.588(\mathrm{TR})$ & 0.680(WS);0.523(TR) & 0.663(WS);0.507(EL) \\
\hline & $0.658(\mathrm{EL})$ & $0.586(\mathrm{EL})$ & $0.516(\mathrm{EL})$ & $0.506(\mathrm{TR})$ \\
\hline Saudi Arabia & $0.571(\mathrm{RE}) ; 0.504(\mathrm{BM})$ & $0.550(\mathrm{RE})$ & $0.505(\mathrm{BM})$ & $0.680(\mathrm{BM}) ; 0.610(\mathrm{WS}) ; 0.548(\mathrm{FI})$ \\
\hline Singapore & NA & $\mathrm{NA}$ & $0.565(\mathrm{WS})$ & $0.598(\mathrm{WS})$ \\
\hline Slovak Republic & $0.503(\mathrm{WS})$ & $0.526(\mathrm{WS})$ & $0.519(\mathrm{WS})$ & $0.532(\mathrm{WS})$ \\
\hline Slovenia & $0.545(\mathrm{WS}) ; 0.530(\mathrm{RD})$ & NA & NA & NA \\
\hline S. Africa & NA & NA & NA & $0.538(\mathrm{WS}) ; 0.518(\mathrm{MI})$ \\
\hline Switzerland & $0.530(\mathrm{WS})$ & $0.517(\mathrm{WS})$ & $0.532(\mathrm{WS})$ & $0.533(\mathrm{WS})$ \\
\hline UK & $0.531(\mathrm{WS})$ & $0.522(\mathrm{WS})$ & $0.531(\mathrm{WS})$ & $0.512(\mathrm{WS})$ \\
\hline US & $0.506(\mathrm{WS})$ & NA & $0.507(\mathrm{WS})$ & $0.515(\mathrm{RD}) ; 0.504(\mathrm{WS})$ \\
\hline Vietnam & $0.609(\mathrm{WS}) ; 0.545(\mathrm{AC})$ & $0.567(\mathrm{WS})$ & NA & NA \\
\hline
\end{tabular}

*Sectors that are not dominant: Wood and products of wood and cork; Rubber and plastics products; Other non-metallic mineral products; Fabricated metal products; Computer, Electronic and optical equipment; Electrical machinery and apparatus; Motor vehicles, trailers and semi-trailers; Other transport equipment; Manufacturing, recycling; Construction; Hotels and restaurants; Post and telecommunications; Renting of machinery and equipment; Computer and related activities; Public administration and defense; Education; Health and social work; Other community, social and personal services; Private households with employed persons; Taxes less subsidies on intermediate and final products; Total intermediate and final expenditure at purchasers' prices. 


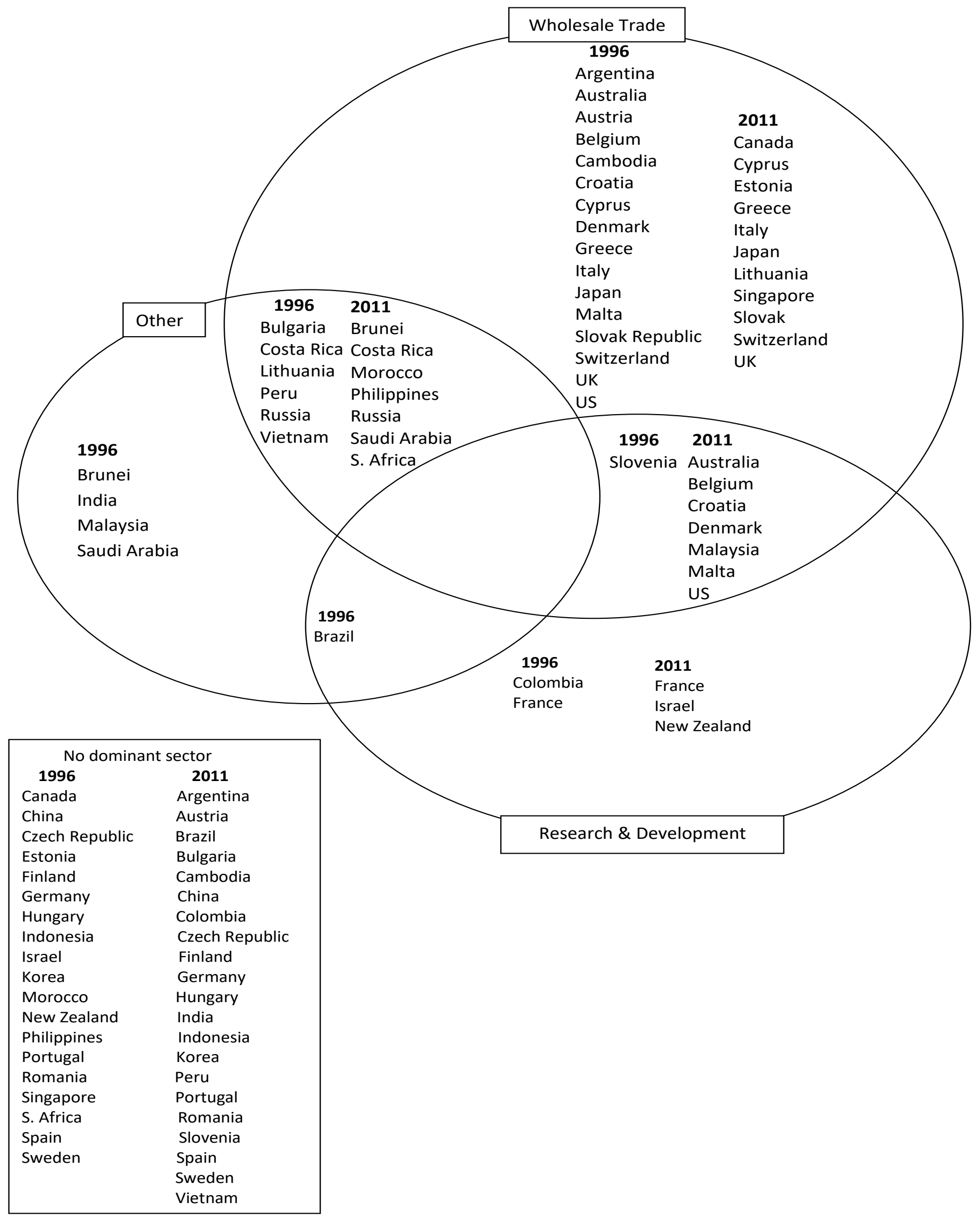

Figure 1: Venn diagram of the dominant sectors by country for 1996 and 2011. 
Figure 1 represents our results for 1996 and 2011 and clearly reveals that in both periods around half of the countries ( 23 in 1996, 25 in 2011) have a dominant wholesale trade sector. Of the 49 economies the box in Figure 1 shows that 21(19) have no single sector which meets the dominance criteria in 2011(1996). By 2011 no country has only dominant sectors outside of wholesale trade and research and development sectors. Brunei and Saudi Arabia have only one "Other" sector dominant in 1996, but by 2011 they each have more than one dominant sector (including wholesale trade). Over the sample, of the possible 36 sectors, 14 are dominant in at least one market, and 22 sectors have no instances of dominance in the economies examined (these sectors are listed under Table 1).

The economies with a dominant R\&D sector by 2011 are overwhelmingly advanced economies the exceptions are Malaysia, and Croatia. Countries where results did not support a dominant sector with $\hat{\delta}_{i}>0.5$, shown in the box, are equally distributed between emerging markets and advanced economics in 1996. By 2011 these were predominantly emerging markets, split between Asia, Latin America and peripheral Europe. ${ }^{8}$ Although it is tempting to associate the results for the small open European countries with their proximity to more developed neighbors as per Coe and Helpman (1995), Rodríguez-Pose and Crescenzi (2008) find this effect is relatively small and depends mainly on the skills of their populations; Marrocu et al. (2013) emphasize even more strongly the role of a highly educated workforce in developing and transmitting R\&D skills.

The combination of the results in Table 1 and the Venn diagram given in Figure 1 suggest a dynamic for the progression of the sectoral structure of economies through time. We note a general progression, aligned with development stage according to the IMF World Economic Outlook classification of advanced and developing countries, where a clockwise progression from "other" dominant sector towards R\&D dominant sectors is evident amongst the countries. For example, the markets shown in the intersection of the $R \& D$ and wholesale trade sector in Figure 1 in 2011 were all identified as having only a dominant wholesale trade sector in 1996 - with the exception of Malaysia which previously had a dominant Financial Institutions sector. While the time frame examined does not allow us to track the progression of an individual country through all the stages, it is evident that countries do move in a generally clockwise direction. Markets may also, at any stage, show no evident dominant sector. This is consistent with a transition period where the changing sectoral structure means that all sectors fail the $\hat{\delta}_{i}>0.5$ test for dominance. For example this appears to be the case exposed by the presence of Israel, Slovenia and South Africa in the no dominant sector box in 1996, but with dominant R\&D sectors by 2011. We also see evidence that some unfortunate countries, exposed to poor circumstances, do seem to regress, for example Slovenia and Colombia.

\section{Conclusion}

The contention of this paper is that two important sectors exist in most economies which are critical to the continued smooth operations of that economy. Removal of either wholesale trade

${ }^{8}$ This finding is different from Fadinger et al. (2016) who report that in emerging countries a distribution of sectoral Leontief inverse elements (right tail) is more asymmetric. 
or the R\&D sectors would have potentially catastrophic effects on the rest of the economy. While the impact of the destruction of trade and transport infrastructure has been witnessed before, in times of conflict or natural disaster, the vulnerability of an economic network to the role of R\&D appears to be less well documented. Despite the clear understanding of $R \& D$ in driving innovation in the economic growth literature, less has been written about the consequences of disinvestment in this sector once it has obtained dominance in a country's economic network.

The implications of our results are that R\&D provides critical infrastructure to the economy just as much as traditional built infrastructure, and this is particularly the case as economies become more developed $^{9}$. In the information age, $R \& D$ proves to be a key sector for many economies, evidenced by the increasing number of economies with dominant research and development sectors in the 21st century, consistent with results of Perez-Sebastian (2015). It behoves us to beware of reducing investment in $R \& D$ in just such a way as we would not destroy critical physical infrastructure. Infrastructure in both cases needs maintenance to continue to allow the economy to function as well as possible.

\section{References}

Acemoglu, D., Carvalho, V.M., Ozdaglar, A., and Tahbaz-Salehi, A. 2012. The network origins of aggregate fluctuations. Econometrica, 80, 1977-2016.

Ando, S. 2014. Measuring US sectoral shocks in the world input-output network. Economics Letters, 125, 204-207.

Bartelme, D., and Gorodnichenko, Y. 2015. Linkages and economic development. NBER, 21251, $1-72$.

Coe, D.T., and Helpman, E. 1995. International R\&D spillovers. European Economic Review, 39, 859-887.

Diebold, F.X., and Yllmaz, K. 2014. On the network topology of variance decompositions: measuring the connectedness of financial firms. Journal of Econometrics, 182, 119-134.

Fadinger, H., Ghiglino, C., and Teteryatnikova, M. 2016. Income differences and input-output structure. SSRN, 11547, 1-62.

Foerster, A., Sarte, P.D., and Watson, M. 2011. Sectoral versus aggregate shocks: A structural factor analysis of industrial production. Journal of Political Economy, 119, 1-38.

Gabaix, X. 2011. The granular origins of aggregate fluctuations. Econometrica, 79, 733-772.

Marrocu, E., Paci, R., and Usai, S. 2013. Proximity, networking and knowledge production in Europe: what lessons for innovation policy? Technological Forecasting and Social Change, 80, $1484-1498$.

\footnotetext{
${ }^{9}$ We draw attention to the extensions of the theoretical framework to take into account sectoral frictions for developing more specific policy recommendations (see for example Fadinger et al., 2016).
} 
Miranda-Pinto, J. 2017. Production network density and aggregate volatility. Job market paper, $1-62$.

Nordhaus, W.D. 2002. Productivity growth and the new economy. Brookings Papers on Economic Activity, 2002, 211-267.

Perez-Sebastian, F. 2015. Market failure, government inefficiency, and optimal R\&D policy. Economics Letters, 128, 43-47.

Pesaran, M.H., and Yang, C.F. 2017. Econometric analysis of production networks with dominant units. SSRN, 6141, 1-61.

Rodríguez-Pose, A., and Crescenzi, R. 2008. Research and development, spillovers, innovation systems, and the genesis of regional growth in Europe. Regional Studies, 42, 51-67. 